\title{
Lathosterol in plasma measures cholesterol synthesis and identifies the efficiency of dietary phytosterols in reducing the plasma cholesterol concentration
}

Valeria Sutti Nunes ( $\nabla$ valeriasutti@gmail.com )

Hospital das Clinicas HCFMUSP, Faculdade de Medicina, Universidade de Sao Paulo https://orcid.org/0000-0002-6769-5412

Angela Oliveira Godoy llha

Laboratorio de Lipides (LIM10), Hospital das Clinicas HCFMUSP, Faculdade de Medicina, Universidade de Sao Paulo

\section{Guilherme Silva Ferreira}

LABORATORIO DE LIPIDES (LIM 10), HOSPITAL DAS CLINICAS HCFMUSP, FACULDADE DE MEDICINA, UNIVERSIDADE DE SAO PAULO

\section{Renata Paula Assis Bombo}

LABORTATORIO DE LIPIDES (LIM 10), HOSPITAL DAS CLINICAS HCFMUSP, FACULDADE DE MEDICINA, UNIVERSIDADE DE SAO PAULO

\section{Milessa Silva Afonso}

LABORATORIO DE LIPIDES (LIM10), HOSPITAL DAS CLINICAS HCFMUSP, FACULDADE DE MEDICINA, UNIVERSIDADE DE SAO PAULO

\section{Roberta Marcondes Machado}

LABORATORIO DE LIPIDES (LIM 10), HOSPITAL DAS CLINICAS HCFMUSP, FACULDADE DE MEDICINA, UNIVERSIDADE DE SAO PAULO

\section{Edna Regina Nakandakare}

LABORATORIO DE LIPIDES (LIM 10), HOSPITAL DAS CLINICAS HCFMUSP, FACULDADE DE MEDICINA, UNIVERSIDADE DE SAO PAULO

\section{Eder Carlos Rocha Quintão}

LABORATORIO DE LIPIDES (LIM 10), HOSPITAL DAS CLINICAS HCFMUSP, FACULDADE DE MEDICINA, UNIVERSIDADE DE SAO PAULO

\section{Ana Maria Maria Lottenberg}

LABORATORIO DE LIPIDES (LIM 10), HOSPITAL DAS CLINICAS HCFMUSP, FACULDADE DE MEDICINA, UNIVERSIDADE DE SAO PAULO

\section{Research}

Keywords: cholesterol, lathosterol, phytosterols, diet

Posted Date: May 7th, 2020 
DOI: https://doi.org/10.21203/rs.3.rs-26174/v1

License: (a) (i) This work is licensed under a Creative Commons Attribution 4.0 International License. Read Full License 


\section{Abstract \\ Background}

Because the plasma campesterol/cholesterol ratio does not differ between groups that absorb different amounts of cholesterol measured by the gold standard isotopic procedure we investigated whether the intestinal absorption of phytosterols (PS) depends on the body's cholesterol synthesis rate.

\section{Methods}

38 volunteers ( $58 \pm 12$ years; low-density lipoprotein cholesterol (LDL-C) $\geq 130 \mathrm{mg} / \mathrm{dL}$ ) were randomly assigned to consume $400 \mathrm{~mL} /$ day of soy milk or soy milk + PS (1.6 g/day) for 4 weeks in a double-blind, placebo-controlled, cross-over study. Blood samples were collected and markers of phytosterol (PS) absorption and non-cholesterol sterol synthesis precursors measured.

\section{Results}

PS treatment reduced plasma total cholesterol concentration $(-5,5 \%, p<0.001)$, LDL-C $(-7.6 \%, p<0.001)$, triglycerides $(-13.6 \%, p<0.0085)$, and apolipoprotein $\mathrm{B}$ (apo B) $(-6.3 \%, p<0.008)$, without changing high density lipoprotein cholesterol (HDL-C concentration). The lathosterol-to-cholesterol ratio in serum predicted the serum cholesterol response to PS feeding where high basal cholesterol synthesis was associated with lack of response of plasma cholesterol to PS in the diet. Cholesterol synthesis being elevated in the placebo phase in non-responders to dietary PS indicated they were resistant to further synthesis rise, whereas responders, because they have lower synthesis rate than non-responders in the placebo phase, are capable expanding synthesis under the effect of alimentary PS.

\section{Conclusions}

responders absorbed more PS than non-responders likely resulting from responders delivering less endogenous cholesterol than non-responders into the intestinal lumen that facilitates greater absorption of PS by the intestine.

\section{Introduction}

It is well known that phytosterols (PS) reduce plasma total cholesterol and low-density lipoproteins cholesterol (LDL-C) [1] [2] [3] due to displacement of cholesterol from the intestinal lumen micelles [4] [5] and for exerting their molecular actions inside enterocytes and hepatocytes [6]. Moreover, it was also demonstrated that PS could induce LDL receptor expression [7]. Because of the beneficial effects on lipid profile, the 2001 National Cholesterol Education Program (NCEP ATP-III) (National Cholesterol Education Program Expert Panel) included PS in the dietary treatment for moderate hypercholesterolemia [8]. However, after the publication of this guideline, some reports have shown that high PS plasma and tissue 
concentrations related to increase on cardiovascular risk [9] [10]. Nevertheless, Bombo et al. [11]clearly showed that LDL receptor knockout mice fed a high saturated fat diet supplemented with $2 \mathrm{~g}$ of PS did not accumulate sterols on aortic valve or arterial wall. On the other hand, PS treatment prevented atherosclerotic lesion development in hypercholesterolemic mice models [11].

Plasma concentrations of PS, and of non-cholesterol sterol precursors of cholesterol synthesis, respectively, markers of the intestinal cholesterol absorption and of the body's cholesterol synthesis have been utilized as markers of atherosclerotic cardiovascular disease [12] [13] [14] [15] [16] [17]. Nonetheless, objections of diverse nature have been raised on the interpretation of the results utilizing plasma PS measurements as markers of intestinal cholesterol absorption and non-cholesterol precursors as markers of cholesterol synthesis. In this regard, high plasma PS were reported inappropriate cholesterol absorption surrogates because PS in the diet lowered the intestinal cholesterol absorption rate [18]. Furthermore, in an investigation on moderate hypercholesterolemia, the plasma campesterol/cholesterol ratio did not differ between groups that absorb different amounts of cholesterol measured by the gold standard isotopic procedure [19]. Therefore, elevation of plasma PS may represent defect in the body's efficiency to re-excrete PS and not an increase in the intestinal absorption of dietary cholesterol. In this regard it is important to take into account that the biliary excretion of plasma PS was more efficient than of plasma cholesterol [20]. Retention of PS in plasma and other tissues may not be due to their increased absorption by intestinal mucosal cells. Consequently, it is questionable whether increased intestinal uptake of PS relates to premature atherosclerosis in humans. Accordingly, cardiovascular disease (CVD) mortality related reciprocally with PS (sitosterol) as a cholesterol absorption marker: the high desmosterol/sitosterol ratio suggested high cholesterol synthesis and low absorption associated with high total and CVD mortality [21]. Nonetheless, low serum lathosterol, but not absorption markers, had also been associated with increased CVD [17]. In contrast, as expected, increased excretion of endogenous cholesterol, which represents increased synthesis, was negatively associated with carotid intima-media thickness [22]. Consequently, the validity of the role on cardiovascular risk of the serum sterol synthesis and absorption markers remains questionable.

In one study in children dietary PS altered the PS concentration in serum but not the concentrations of cholesterol synthesis precursors [23]. Contrarily, in one study on low cholesterol synthesis cases during the placebo period it was shown that high intestinal sitosterol absorption occurred on PS feeding [24] but the latter was not mentioned in the other study [25].

To investigate these previous discrepancies, we measured in plasma the concentrations of precursors of cholesterol synthesis and PS as markers of intestinal absorption of cholesterol in the placebo phase and after ingestion of PS.

\section{Methods}

\section{Subject recruitment}

The individuals ( $n=38$ : female 31 and male 7) aged 38-77 years were recruited in the Dyslipidemia Outpatient Unit of the Endocrinology and Metabolism Service of the Clinical Hospital of the University of Sao Paulo, Brazil; members of the staff of the University of Sao Paulo, Brazil were also included. The participants 
were invited for screening of body weight and height; blood samples were collected for lipids profile determination. The inclusion criteria were: body mass index (BMI) between 20 and $30 \mathrm{~kg} / \mathrm{m}^{2}$; total cholesterol between $200-300 \mathrm{mg} / \mathrm{dL}, \mathrm{LDL}-\mathrm{C}$ concentrations $\geq 130 \mathrm{mg} / \mathrm{dL}$, and triglycerides $\leq 250 \mathrm{mg} / \mathrm{dL}$ (Table 1). Exclusion criteria were: use of lipid-lowering medication or a prescribed diet in the last month; alcohol abuse or illicit drug users; pregnancy or breast feeding; smoking; diabetes mellitus, hypothyroidism, renal or hepatic diseases or participation in another lifestyle or pharmaceutical intervention studies. All subjects provided informed written consent. The Ethics in Research Committee of the Hospital of the University of Sao Paulo Medical School approved the study protocol (CAPPesq $n^{\circ} 112 / 06$ ).

Table 1

Subjects characteristics at baseline

\begin{tabular}{|l|l|}
\hline Parameter & Mean \pm SD \\
\hline $\mathrm{n}$ & 38 \\
\hline Age (years) & $58 \pm 12$ \\
\hline Weight $(\mathrm{Kg})$ & $64 \pm 10$ \\
\hline BMI $\left(\mathrm{kg} / \mathrm{m}^{2}\right)$ & $25.3 \pm 2.4$ \\
\hline Total cholesterol $(\mathrm{mg} / \mathrm{dL})$ & $245 \pm 34$ \\
\hline Triglycerides $(\mathrm{mg} / \mathrm{dL})$ & $141 \pm 53$ \\
\hline LDL-C $(\mathrm{mg} / \mathrm{dL})$ & $165 \pm 34$ \\
\hline HDL-C $(\mathrm{mg} / \mathrm{dL})$ & $49 \pm 12$ \\
\hline $\begin{array}{l}\text { BMI, body } \mathrm{mass} \text { index; LDL-C, low-density lipoprotein cholesterol; HDL-C: high density lipoprotein } \\
\text { cholesterol }\end{array}$ \\
\hline
\end{tabular}

\section{Study Design}

The present study was a randomized, double-blind, placebo-controlled dietary intervention trial with each study period lasting 4 weeks. Initially, all the participants were submitted to a 3-week run-in period in which they received the placebo product (soy milk) to test adherence to the protocol. After baseline period the individuals were randomly assigned to placebo or to phytosterol groups for 4 weeks; after that a reverse sequence was immediately carried out. Placebo group received $400 \mathrm{~mL}$ of soy milk daily; phytosterol group received $400 \mathrm{~mL}$ of soy milk enriched with $1.6 \mathrm{~g}$ of PS, as follow: $78 \% \beta$-sitosterol-ester, $13 \%$ sitostanol-ester, $5.3 \%$ campesterol-ester and $0.5 \%$ campestanol-ester (Table 2). Blood samples were drawn for biochemical analysis from fasting participants on the last day of each period study. All participants were advised to maintain body weight and follow a normocaloric diet based on the NCEP-ATPIII recommendation [8]: $30 \%$ of energy as fat, $<10 \%$ of energy as saturated fat, and $<300 \mathrm{mg}$ cholesterol/day and was recommended not to consume products enriched with phytosterol during the study. Nutritional monitoring was carried out by a registered dietitian using a 24-hour dietary recall to ensure adherence to the prescribed diet and also to 
estimate the food intake. Soy milk was weekly supplied at the same day of the body weight measurement; patients were instructed to consume the soy milk or PS-enriched soy milk twice daily, at lunch and dinner.

Table 2

Soy milk nutritional composition per portion $(200 \mathrm{~mL})$ *.

\begin{tabular}{|lll|}
\hline Nutritional composition & Soy milk & Soy milk + PS \\
\hline Energy (kcal) & 138 & 144 \\
\hline Protein (g) & 6.5 & 6.5 \\
\hline Total fat (g) & 4.4 & 5.0 \\
\hline Polyunsaturated fat & 2.3 & 2.5 \\
\hline Monounsaturated fat & 1.0 & 1.1 \\
\hline Saturated fat & 0.7 & 0.9 \\
\hline Trans fatty acid & 0 & 0 \\
\hline Cholesterol (mg) & 0 & 0 \\
\hline Carbohydrates (g) & 18.2 & 18.2 \\
\hline Total sugar & 14.1 & 14.1 \\
\hline Lactose & 0 & 0 \\
\hline Phytosterol (g) & 0 & 0.8 \\
\hline B-sitosterol-ester & & 0.63 \\
\hline Sitostanol-ester & & 0.10 \\
\hline Campesterol-ester & & 0.05 \\
\hline Campestanol-ester & & 0.005 \\
\hline Sodium (g) & 0.1 & 0.1 \\
\hline *Provided by Nestle Company, São Paulo, Brazil \\
\hline
\end{tabular}

\section{Blood Sampling}

After fasting for 12 hours, blood samples were collected into tubes containing Ethylenediamine tetraacetic acid (EDTA). Plasma was immediately separated by centrifugation (1300 g, $15 \mathrm{~min}, 4^{\circ} \mathrm{C}$; RT6000B; Sorvall Instruments, DuPont Co, Newton, CT), and the following preservatives were added: $0.25 \%$ chloramphenicol plus $0.5 \%$ gentamycin $(20 \mu \mathrm{L} / \mathrm{mL}), 2 \mathrm{mmol}$ benzamidine/L $(5 \mu \mathrm{L} / \mathrm{mL}), 10 \mathrm{mmol}$ phenyl-methyl-sulfonyl fluoride/L $(0.5 \mu \mathrm{L} / \mathrm{mL})$, and aprotinin $(0.5 \mu \mathrm{L} / \mathrm{mL})$. For HDL-C measurements, plasma was mixed and kept at room temperature for $10 \mathrm{~min}$ and then centrifuged $\left(700 \mathrm{~g}, 30 \mathrm{~min}, 4^{\circ} \mathrm{C}\right)$. Aliquots $(500 \mu \mathrm{L})$ were stored at $-70^{\circ} \mathrm{C}$. Total plasma and serum were stored at $-70^{\circ} \mathrm{C}$. All measurements were performed in duplicate at the end of the study. All samples from one subject were analyzed within the same analytical run. 


\section{Serum Sterols Analyses}

Plasma precursors of cholesterol synthesis (desmosterol, lathosterol) and phytosterols (campesterol and sitosterol) were measured in samples $(100 \mu \mathrm{L})$ added $5 \mathrm{a}$-cholestane $(1 \mu \mathrm{g})$ as the internal standard, hydrolyzed with $\mathrm{KOH}$ in ethanol $(1 \mathrm{~mol} / \mathrm{l}, 1 \mathrm{ml})$ at $60{ }^{\circ} \mathrm{C}(1 \mathrm{~h})$ and extracted with hexane. Sterols were derivatized with a sylilating solution (pyridine and BSTFA (N,O-bis (trimethylsilyl) trifluoroacetamide) $+1 \%$ TMCS (trimethylchlorosilane) $(1: 1, \mathrm{v} / \mathrm{v})$ (Supelco $33155-\mathrm{U})$ for $1 \mathrm{~h}$ at $60^{\circ} \mathrm{C}[28]$. The quantification was performed comparing the peak areas of the standard curve and corrected for internal standards. Plasma noncholesterol sterols $(\mu \mathrm{g})$ were expressed as ratio of plasma total cholesterol $(\mathrm{mg})$.

\section{Statistical analysis}

Comparisons between the placebo and phytosterol groups were analysed by paired Student's t test. The influence of degree of hypercholesterolemia over the PS response and PS response patterns related to LDL-C were analysed by unpaired Student's $t$ test. Data are shown as means and standard deviation. The analyses were performed utilizing the GraphPad Prisma version 4.00 and significance level considered as $p<0.05$.

\section{Results}

The study was initiated with 40 subjects but two of them were excluded for presenting more than $5 \%$ of weight variation along the study. The body weight and the BMI of the participants remained unaltered throughout the study (Table 3). As demonstrated in several studies, PS reduced total cholesterol, LDL-C, apo B and triglycerides without affecting HDL-C plasma concentrations. As expected, PS supplementation increased plasma lathosterol as well as campesterol and $\beta$-sitosterol (indicating compliance to the diets). Lathosterol increased in plasma as a consequence of the blockade of the absorption of cholesterol exerted by PS ingestion. However, the lathosterol / phytosterols ratios decreased due to the higher absorption of PS. 
Table 3

Body weight, BMI, biochemical analysis, plasma sterol concentrations of moderately hypercholesterolemic patients.

\begin{tabular}{|c|c|c|c|c|}
\hline & $\mathbf{n}$ & Placebo & Phytosterol & $\mathbf{p}$ \\
\hline Body weight $(\mathrm{kg})$ & 38 & $64.9 \pm 10.2$ & $65.1 \pm 10.3$ & 0.08 \\
\hline $\mathrm{BMI}\left(\mathrm{kg} / \mathrm{m}^{2}\right)$ & 38 & $25.4 \pm 0.4$ & $25.4 \pm 0.4$ & ns \\
\hline Total cholesterol $(\mathrm{mg} / \mathrm{dL})$ & 38 & $261 \pm 7.1$ & $244 \pm 5.8^{*}$ & $<0.001$ \\
\hline $\mathrm{HDL}-\mathrm{C}(\mathrm{mg} / \mathrm{dL})$ & 38 & $46 \pm 1.7$ & $48 \pm 1.9$ & ns \\
\hline LDL-C (mg/dL) & 38 & $183 \pm 5.9$ & $169 \pm 5.2^{*}$ & 0.001 \\
\hline ApoB (mg/dL) & 38 & $126 \pm 3.7$ & $118 \pm 3.2^{*}$ & 0.006 \\
\hline Triglycerides $(\mathrm{mg} / \mathrm{dL})$ & 38 & $154 \pm 10$ & $133 \pm 7^{*}$ & 0.008 \\
\hline \multicolumn{5}{|c|}{ Plasma sterols expressed as $\mu \mathrm{g} / \mathrm{mg}$ cholesterol } \\
\hline Lathosterol & 38 & $1.53 \pm 0.09$ & $1.69 \pm 0.06^{*}$ & 0.012 \\
\hline Campesterol & 38 & $1.96 \pm 0.12$ & $2.34 \pm 0.11^{*}$ & 0.02 \\
\hline$\beta$-sitosterol & 38 & $1.64 \pm 0.09$ & $2.02 \pm 0.09^{*}$ & $<0.001$ \\
\hline Lathosterol/campesterol ratio & 38 & $0.85 \pm 0.05$ & $0.76 \pm 0.03^{*}$ & $<0.001$ \\
\hline Lathosterol/ $\beta$-sitosterol ratio & 38 & $1.03 \pm 0.05$ & $0.88 \pm 0.04^{*}$ & $<0.001$ \\
\hline
\end{tabular}

In order to investigate whether the degree of hypercholesterolemia influenced the PS response, patients were divided according to tertiles of LDL-C at baseline ( $<168 \mathrm{mg} / \mathrm{dL}$ and $>187 \mathrm{mg} / \mathrm{dL}$ ) (Table 4). Placebo minus phytosterol data variations are expressed as delta values. PS intake effectively reduced LDL-C and apo B concentrations in both groups but failed to modify triglycerides concentrations

Furthermore, serum concentration of lathosterol, campesterol and sitosterol were higher in the LDL-C $<148$ than in LDL-C > 187 tertiles, but failed to change on PS feeding. 
Table 4

Patients according to the averages of LDL-C tertiles at baseline $(<168 \mathrm{mg} / \mathrm{dL}$ and $>187 \mathrm{mg} / \mathrm{dL})$

\begin{tabular}{|c|c|c|c|c|}
\hline & & LDL-C $<168$ & LDL-C $>187$ & p \\
\hline \multirow[t]{4}{*}{ LDL (mg/dL) } & Placebo & $150 \pm 14$ & $215 \pm 20$ & $<0.0001$ \\
\hline & & $n=13$ & $\mathrm{n}=12$ & \\
\hline & Phytosterol & $148 \pm 15$ & $192 \pm 24$ & $<0.0001$ \\
\hline & & $n=13$ & $n=12$ & \\
\hline Delta LDL-C (\%) & & $-0.5 \pm 13$ & $-10.3 \pm 12$ & ns \\
\hline Delta LDL-C (mg) & & $-1.9 \pm 18.1$ & $-23.0 \pm 26.1$ & 0.0269 \\
\hline \multirow[t]{4}{*}{ ApoB (mg/dL) } & Placebo & $110 \pm 10$ & $151 \pm 22$ & $<0.0001$ \\
\hline & & $n=13$ & $n=13$ & \\
\hline & Phytosterol & $112 \pm 14$ & $131 \pm 22$ & 0.0120 \\
\hline & & $n=13$ & $n=13$ & \\
\hline Delta ApoB (\%) & & $1.8 \pm 10.1$ & $-12.5 \pm 10.2$ & 0.0019 \\
\hline Delta ApoB (mg) & & $1.8 \pm 11.5$ & $-19.3 \pm 17.5$ & 0.0013 \\
\hline \multirow[t]{4}{*}{ Triglycerides (mg/dL) } & Placebo & $96 \pm 7$ & $130 \pm 14$ & $<0.0001$ \\
\hline & & $n=13$ & $n=13$ & \\
\hline & Phytosterol & $115 \pm 38$ & $148 \pm 44$ & 0.0472 \\
\hline & & $n=13$ & $n=13$ & \\
\hline Delta triglycerides (\%) & & $22 \pm 36$ & $15 \pm 38$ & ns \\
\hline Delta triglycerides (mg) & & $19 \pm 42$ & $18 \pm 47$ & ns \\
\hline Lathosterol & Placebo & $1.689 \pm 0.314$ & $1.372 \pm 0.303$ & 0.0221 \\
\hline \multirow[t]{3}{*}{ ( $\mu \mathrm{g} / \mathrm{mg}$ cholesterol) } & & $n=11$ & $n=12$ & \\
\hline & Phytosterol & $1,887 \pm 0,250$ & $1,522 \pm 0,233$ & 0.0016 \\
\hline & & $n=11$ & $n=12$ & \\
\hline Delta lathosterol (\%) & & $13,73 \pm 15,42$ & $14,15 \pm 22,77$ & ns \\
\hline Delta lathosterol $(\mu \mathrm{g} / \mathrm{mg})$ & & $0,197 \pm 0,214$ & $0,150 \pm 0,286$ & ns \\
\hline Campesterol & Placebo & $2.370 \pm 0.633$ & $1.391 \pm 0.345$ & 0.0002 \\
\hline ( $\mu \mathrm{g} / \mathrm{mg}$ cholesterol) & & $\mathrm{n}=11$ & $\mathrm{n}=12$ & \\
\hline
\end{tabular}




\begin{tabular}{|c|c|c|c|c|}
\hline & & LDL-C $<168$ & LDL-C $>187$ & p \\
\hline & Phytosterol & $2,881 \pm 0,754$ & $1,941 \pm 0,518$ & 0.0028 \\
\hline & & $\mathrm{n}=11$ & $\mathrm{n}=11$ & \\
\hline Delta campesterol (\%) & & $25,43 \pm 32,30$ & $40,71 \pm 20,73$ & ns \\
\hline Delta campesterol ( $\mu \mathrm{g} / \mathrm{mg})$ & & $0,511 \pm 0,704$ & $0,550 \pm 0,280$ & ns \\
\hline Sitosterol & Placebo & $1.952 \pm 0.445$ & $1.196 \pm 0.283$ & 0.0001 \\
\hline \multirow[t]{3}{*}{ ( $\mu \mathrm{g} / \mathrm{mg}$ cholesterol) } & & $\mathrm{n}=11$ & $\mathrm{n}=11$ & \\
\hline & Phytosterol & $2,484 \pm 0,518$ & $1,693 \pm 0,451$ & 0.0011 \\
\hline & & $\mathrm{n}=11$ & $\mathrm{n}=11$ & \\
\hline Delta sitosterol (\%) & & $30,16 \pm 26,87$ & $41,91 \pm 17,95$ & ns \\
\hline Delta sitosterol $(\mu \mathrm{g} / \mathrm{mg})$ & & $0,532 \pm 0,506$ & $0,497 \pm 0,242$ & ns \\
\hline
\end{tabular}

We also examined whether PS response patterns related to LDL-C response patterns: some patients were nonresponders $(n=10)$, but most cases were responders $(n=27)$ (Table 5). Placebo minus phytosterol data variations are expressed as delta values. We found in the placebo phase lathosterol higher in non-responders than in responders to PS. However, on PS feeding the concentrations of lathosterol did not differ between the two groups. On the other hand, lathosterol percent variation on PS in relation to the placebo period did not vary in non-responders and increased in responders. This means that non-responders, because they have high synthesis before treatment, could not further expand synthesis on PS treatment. Responders synthesize less in the placebo phase but expand the synthesis rate on PS treatment. 
Table 5

Plasma sterols response patterns defined by LDL-C changes defining patients non-responders and responders to PS treatment.

\begin{tabular}{|c|c|c|c|c|}
\hline & & $\begin{array}{l}\text { Non-responders } \\
(n=10)\end{array}$ & $\begin{array}{l}\text { Responders } \\
(n=27)\end{array}$ & $\mathbf{p}$ \\
\hline \multirow[t]{2}{*}{ LDL-C (mg/dL) } & Placebo & $171 \pm 24$ & $191 \pm 37$ & ns \\
\hline & Phytosterol & $184 \pm 29$ & $165 \pm 32$ & ns \\
\hline Delta LDL-C (\%) & & $8 \pm 5$ & $-13 \pm 7$ & $<0.0001$ \\
\hline Delta LDL-C (mg/dL) & & $14 \pm 9$ & $-26 \pm 15$ & $<0.0001$ \\
\hline Lathosterol & Placebo & $1,929 \pm 0,954$ & $1,463 \pm 0,363$ & 0.0379 \\
\hline ( $\mu \mathrm{g} / \mathrm{mg}$ cholesterol) & Phytosterol & $1,658 \pm 0,411$ & $1,686 \pm 0,344$ & ns \\
\hline Delta lathosterol (\%) & & $-8 \pm 16$ & $18 \pm 19$ & 0.0009 \\
\hline Campesterol & Placebo & $2,242 \pm 0,898$ & $1,831 \pm 0,610$ & ns \\
\hline ( $\mu \mathrm{g} / \mathrm{mg}$ cholesterol) & Phytosterol & $2,168 \pm 0,582$ & $2,401 \pm 0,755$ & ns \\
\hline Delta campesterol (\%) & & $3 \pm 25$ & $34 \pm 26$ & 0.0053 \\
\hline Sitosterol & Placebo & $1,958 \pm 0,860$ & $1,529 \pm 0,469$ & ns \\
\hline ( $\mu \mathrm{g} / \mathrm{mg}$ cholesterol) & Phytosterol & $1,841 \pm 0,532$ & $2,075 \pm 0,595$ & ns \\
\hline Delta sitosterol (\%) & & $1 \pm 26$ & $38 \pm 23$ & 0.0007 \\
\hline
\end{tabular}

\section{Discussion}

As expected, the consumption of PS-enriched soy milk significantly lowered total cholesterol (-5.5\%) and LDLC (-7.6\%). The very mild cholesterol reduction could be attributed to a small PS intake in this study as compared to other investigations [29] [30]. However, the blood cholesterol variation was intense enough to identify different patterns of metabolic changes. Furthermore, a wide variability in individual LDL-C plasma reduction in response to PS intake was previously reported by us [1]. PS also reduced apoB-LP likely belonging to LDL, but increased TG plasma concentrations as compared to placebo especially in participants presenting higher LDL-C concentrations at baseline.

Present investigation confirms previous studies showing that the lathosterol-to-cholesterol ratio in serum predicted the serum cholesterol response to PS feeding where high basal cholesterol synthesis is associated with lack of response of plasma cholesterol [24,25], and contradicts another study in children in which dietary PS alters the concentration of PS in serum but not the serum concentration of cholesterol synthesis precursors [23]. In one study during the placebo period it was shown in the low cholesterol synthesis cases 
that high intestinal sitosterol absorption occurred on PS feeding [24] but was not mentioned in the other study [25]. Since the degree of cholesterol absorption indicated by plasma phytosterol concentration could influence cholesterol synthesis in the placebo phase and its response to PS intake, we measured plasma phytosterols concentrations before and after PS feeding. We noted that absorption markers did not differ between responders and non-responders in the placebo phase. Therefore, the difference in responses between the two groups is strictly dependent on the intensity of cholesterol synthesis. However, unlike the non-responders, responders are capable of increasing the absorption of PS most likely because there are small amounts of cholesterol in the intestinal lumen to compete for the intestinal absorption with the alimentary PS. We conclude that elevated synthesis during placebo in non-responders makes them resistant to further synthesis rise on PS treatment, whereas responders, because they have lower synthesis than nonresponders in the placebo phase, are capable expanding synthesis under the effect of alimentary PS.

Interestingly, in the placebo phase, as well as after ingestion of PS, the plasma concentrations of campesterol and sitosterol did not differ between the non-responders and the responder cases. However, as occurred for lathosterol, the percent variation of these markers of absorption on PS feeding over the placebo period was significantly greater in the responders than in the non-responders. This is compatible with the responders absorbing more PS than non-responders. Our data contribute to explain investigation in cases of metabolic syndrome in which decreased intestinal absorption of cholesterol is associated with lower efficiency of PS esters in reducing blood cholesterol although the cholesterol synthesis markers had not been measured [31]. Such a result may be consequent to elevated cholesterol synthesis in cases of metabolic syndrome [16]. In summary, responders absorbed more PS than non-responders likely resulting from responders delivering less endogenous cholesterol into the intestinal lumen that facilitates greater absorption of PS by the intestine.

\section{Abbreviations}

\section{BMI}

body mass index

\section{BSTFA}

$\mathrm{N}, \mathrm{O}$-bis (trimethylsilyl) trifluoroacetamide

\section{EDTA}

ethylenediamine tetraacetic acid

HDL-C

high-density lipoproteins cholesterol

\section{LDL-C}

low-density lipoproteins cholesterol

PS

phytosterols

TMCS

trimethylchlorosilane

\section{Declarations}




\section{Ethics approval and consent to participate}

The Ethics in Research Committee of the Hospital of the University of Sao Paulo Medical School approved the study protocol (CAPPesq $n^{\circ} 112 / 06$ ). All participants were informed of the objectives of the protocol and signed an informed written consente.

\section{Consent for publication}

All the authors have consented for the publication of this study.

\section{Availability of data and materials}

The data used to support the findings of this study are included within the article. Additional data or information can be requested by contacting the corresponding author.

\section{Conflict of Interest}

The founding sponsors had no role in the design of the study; in the collection, analyses, or interpretation of data; in the writing of the manuscript, and in the decision to publish the results

\section{Funding}

This work was supported by UNILEVER (SP, Brazil)

\section{Author contribution}

VSN: Conceptualization, Methodology, Writing - Review \& Editing. AOGI: Conceptualization, Writing - original draft, Investigation, Methodology; MSA, RPAB, RMM: Investigation, Methodology; GSF: Formal analysis; ERN: Formal analysis; ECRQ: Writing - review \& editing; AMPL: Writing - review \& editing, Supervision, Funding acquisition.

\section{Acknowledgements}

Not applicable

\section{References}

1. Lottenberg AMP, Nunes VS, Nakandakare ER, Neves M, Bernik M, Santos JE, et al. [Food phytosterol ester efficiency on the plasma lipid reduction in moderate hypercholesterolemic subjects]. Arquivos brasileiros de cardiologia. 2002. 
2. Acuff RV, Cai DJ, Dong ZP, Bell D. The lipid lowering effect of plant sterol ester capsules in hypercholesterolemic subjects. Lipids in Health Disease. 2007;6:1-10.

3. Cater NB, Garcia-Garcia AB, Vega GL, Grundy SM. Responsiveness of plasma lipids and lipoproteins to plant stanol esters. Am J Cardiol. 2005;96:23-8.

4. Ikeda I, Tanaka K, Sugano M, Vahouny GV, Gallo LL. Inhibition of cholesterol absorption in rats by plant sterols. Journal of lipid research [Internet]. 1988;29:1573-82. Available from: http://www.ncbi.nlm.nih.gov/pubmed/2468730.

5. Field FJ, Born E, Mathur SN. Effect of micellar beta-sitosterol on cholesterol metabolism in CaCo-2 cells. The Journal of Lipid Research [Internet]. 1997;38:348. Available from:

http://www.ncbi.nlm.nih.gov/pubmed/9162754\%5Cnhttp://www.ncbi.nlm.nih.gov/entrez/query.fcgi? $\mathrm{db}=$ pubmed\&cmd=Retrieve\&dopt=AbstractPlus\&list_uids=2802007689439294051 related:YzLx2iW74iYJ.

6. Vanstone CA, Raeini-Sarjaz M, Jones PJH. Injected phytosterols/stanols suppress plasma cholesterol levels in hamsters. J Nutr Biochem. 2001;12:565-74.

7. Plat J, Mensink RP. Effects of plant stanol esters on LDL receptor protein expression and on LDL receptor and HMG-CoA reductase mRNA expression in mononuclear blood cells of healthy men and women. Faseb J. 2002;16:258-60.

8. Third Report of the National Cholesterol Education Program (NCEP) Expert Panel on Detection, Evaluation, and Treatment of High Blood Cholesterol in Adults (Adult Treatment Panel III) Final Report. Circulation [Internet]. American Heart Association; 2002;106:3143. Available from: https://doi.org/10.1161/circ.106.25.3143.

9. Weingärtner O, Lütjohann D, Ji S, Weisshoff N, List F, Sudhop T, et al. Vascular Effects of Diet Supplementation With Plant Sterols. J Am Coll Cardiol. 2008;51:1553-61.

10. Weingartner O, Weingartner N, Scheller B, Lutjohann D, Graber S, Schafers HJ, et al. Alterations in cholesterol homeostasis are associated with coronary heart disease in patients with aortic stenosis. Coron Artery Dis. 2009.

11. Bombo RPA, Afonso MS, Machado RM, Lavrador MSF, Nunes VS, Quintão ER, et al. Dietary phytosterol does not accumulate in the arterial wall and prevents atherosclerosis of LDLr-KO mice. Atherosclerosis. 2013.

12. Matthan NR, Resteghini N, Robertson M, Ford I, Shepherd J, Packard C, et al. Cholesterol absorption and synthesis markers in individuals with and without a CHD event during pravastatin therapy: insights from the PROSPER trial. J Lipid Res. 2010;51:202-9.

13. 10.1194/jlr.P900039-JLR200

Matthan NR, Pencina M, LaRocque JM, Jacques PF, D’Agostino RB, Schaefer EJ, et al. Alterations in cholesterol absorption/synthesis markers characterize Framingham Offspring Study participants with CHD. Journal of Lipid Research [Internet]. 2009;50:1927-35. Available from: http://www.jlr.org/lookup/doi/10.1194/jlr.P900039-JLR200.

14. Dayspring TD, Varvel SA, Ghaedi L, Thiselton DL, Bruton J, McConnell JP. Biomarkers of cholesterol homeostasis in a clinical laboratory database sample comprising 667,718 patients. Journal of Clinical Lipidology. 2015. 
15. Gong Z, Qi Y, Zhao F, Liu J, Wang W, Liu J, et al. [Association between very low density lipoprotein cholesterol and cholesterol absorption/synthesis markers in patients with moderate and high risk of coronary heart disease]. Zhonghua xin xue guan bing za zhi. China. 2015;43:936-42.

16. Mashnafi S, Plat J, Mensink RP, Baumgartner S. Non-Cholesterol Sterol Concentrations as Biomarkers for Cholesterol Absorption and Synthesis in Different Metabolic Disorders: A Systematic Review. Nutrients. 2019;11:124.

17. $10.1007 / \mathrm{s} 00392-019-01474-2$

Weingärtner O, Lütjohann D, Meyer S, Fuhrmann A, Cremers B, Seiler-Mußler S, et al. Low serum lathosterol levels associate with fatal cardiovascular disease and excess all-cause mortality: a prospective cohort study. Clinical Research in Cardiology [Internet]. Springer Berlin Heidelberg; 2019;2-6. Available from: https://doi.org/10.1007/s00392-019-01474-2.

18. 10.1016/j.numecd.2011.11.007

Mackay DS, Jones P. Limitations of lathosterol to plant sterol ratios and serum plant sterols as surrogate markers for cholesterol absorption during plant sterol supplementation. Nutrition, Metabolism and Cardiovascular Diseases [Internet]. Elsevier B.V.; 2012;22:e21. Available from:

http://dx.doi.org/10.1016/j.numecd.2011.11.007.

19. Jakulj L, Mohammed H, van Dijk TH, Boer T, Turner S, Groen AK, et al. Plasma plant sterols serve as poor markers of cholesterol absorption in man. Journal of lipid research United States. 2013;54:1144-50.

20. Sudhop T, Sahin Y, Lindenthal B, Hahn C, Luers C, Berthold HK, et al. Comparison of the hepatic clearances of campesterol, sitosterol, and cholesterol in healthy subjects suggests that efflux transporters controlling intestinal sterol absorption also regulate biliary secretion. Gut England. 2002;51:860-3.

21. Strandberg TE, Gylling H, Tilvis RS, Miettinen TA. Serum plant and other noncholesterol sterols, cholesterol metabolism and 22-year mortality among middle-aged men. Atherosclerosis Ireland. 2010;210:282-7.

22. Lin X, Racette SB, Ma L, Wallendorf M, Dávila-Román VG, Ostlund RE. Endogenous cholesterol excretion is negatively associated with carotid intima-media thickness in humans. Arteriosclerosis, Thrombosis, and Vascular Biology. 2017.

23. Tammi A, Ronnemaa T, Valsta L, Seppanen R, Rask-Nissila L, Miettinen TA, et al. Dietary plant sterols alter the serum plant sterol concentration but not the cholesterol precursor sterol concentrations in young children (the STRIP Study). Special Turku Coronary Risk Factor Intervention Project. The Journal of nutrition United States. 2001;131:1942-5.

24. Mackay DS, Gebauer SK, Eck PK, Baer DJ, Jones PJH. Lathosterol-to-cholesterol ratio in serum predicts cholesterol-lowering response to plant sterol consumption in a dual-center, randomized, single-blind placebo-controlled trial. The American journal of clinical nutrition United States. 2015;101:432-9.

25. Rideout TC, Harding SV, Mackay D, Abumweis SS, Jones PJ. High basal fractional cholesterol synthesis is associated with nonresponse of plasma LDL cholesterol to plant sterol therapy. The American journal of clinical nutrition United States. 2010;92:41-6.

26. Bachorik PS, Albers JJ. Precipitation methods for quantification of lipoproteins. Methods in enzymology United States. 1986;129:78-100. 
27. Friedewald WT, Levy RI, Fredrickson DS. Estimation of the concentration of low-density lipoprotein cholesterol in plasma, without use of the preparative ultracentrifuge. Clinical chemistry United States. 1972;18:499-502.

28. Nunes VS, Leança CC, Panzoldo NB, Parra E, Cazita PM, Nakandakare ER, et al. HDL-C concentration is related to markers of absorption and of cholesterol synthesis: Study in subjects with low vs. high HDL-C. Clinica Chimica Acta. 2011;412.

29. De Jong A, Plat J, Bast A, Godschalk RWL, Basu S, Mensink RP. Effects of plant sterol and stanol ester consumption on lipid metabolism, antioxidant status and markers of oxidative stress, endothelial function and low-grade inflammation in patients on current statin treatment. European journal of clinical nutrition England. 2008;62:263-73.

30. Bombo RPA, Afonso MS, Machado RM, Lavrador MSF, Nunes VS, Quintão ER, et al. Dietary phytosterol does not accumulate in the arterial wall and prevents atherosclerosis of LDLr-KO mice. Atherosclerosis. 2013;231.

31. Hernandez-Mijares A, Banuls C, Jover A, Sola E, Bellod L, Martinez-Triguero ML, et al. Low intestinal cholesterol absorption is associated with a reduced efficacy of phytosterol esters as hypolipemic agents in patients with metabolic syndrome. Clinical nutrition (Edinburgh, Scotland). England. 2011;30:604-9. 